\title{
Editorial: Special Issue in Memoriam Heinz Gamsjäger
}

\author{
Erich Königsberger $^{1}$ (D) $\cdot$ LanChi Königsberger ${ }^{1} \cdot$ Peter Gärtner $^{2}$
}

Received: 12 January 2018/ Accepted: 15 January 2018/Published online: 1 February 2018

(C) Springer-Verlag GmbH Austria, part of Springer Nature 2018

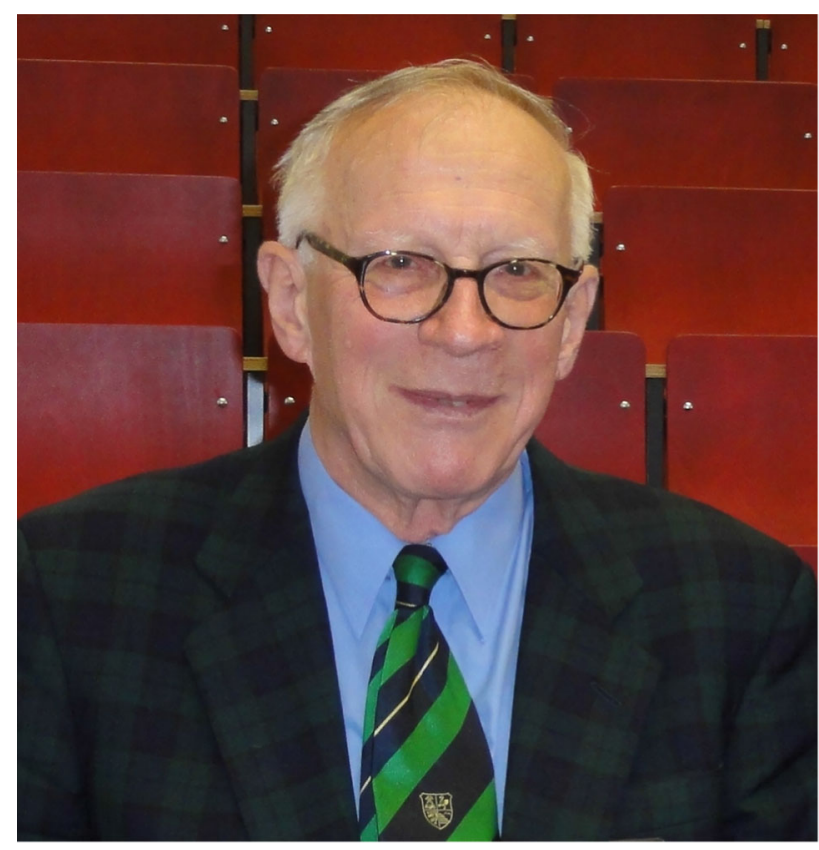

Emeritus Professor Dipl.-Ing. Dr. mont. Heinz Gamsjäger (30 June 1932 - 30 October 2016) Photo taken at the $14^{\text {th }}$ International Symposium on Solubility Phenomena (ISSP-14), which was organised by him at Montanuniversität Leoben, Austria, in July 2010.
Professor Heinz Gamsjäger was an Associate Editor of Monatshefte für Chemie/Chemical Monthly since 1998. His almost 20 years of service was an invaluable contribution to the Journal. Professor Gamsjäger was taking care of manuscripts in the field of Physical Chemistry, particularly focusing on solubility phenomena, the most prominent of his research interests. In his role as an Editor, he meticulously applied his expertise to make sure that everything was precise and well defined in all articles in his area. Professor Gamsjäger identified himself with Monatshefte für Chemie/Chemical Monthly which was one of the reasons that he was so enthusiastic to promote the Journal within his network of chemists and motivate colleagues to publish here. Professor Gamsjäger was a very dedicated and passionate person and we will keep him as such in our minds.

This Memorial Issue is honouring Professor Gamsjäger and his contributions to chemical thermodynamics, including the accurate measurement of solubility equilibria, the calculation and optimization of phase diagrams, modelling of geochemical and metallurgical processes, and the assessment and critical evaluation of thermodynamic data. The authors of the contributions to this special issue were friends and colleagues of Professor Gamsjäger, many of whom worked closely with him in the IUPAC Subcommittee on Solubility and Equilibrium Data. The scientific topics of this special issue align with Professor Gamsjäger's varied research interests.
Erich Königsberger

E.Koenigsberger@murdoch.edu.au

1 Murdoch University, Murdoch, Australia

2 Vienna University of Technology, Vienna, Austria 


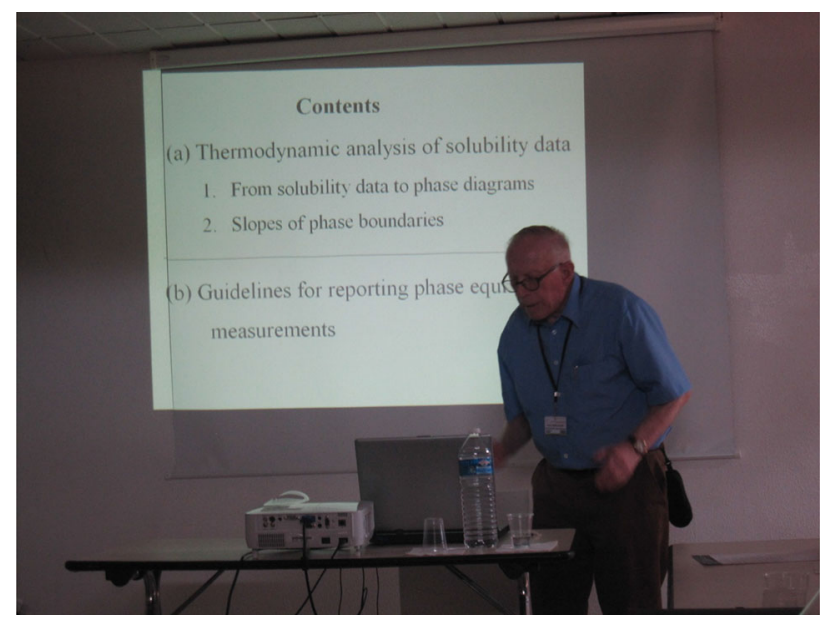

Professor Gamsjäger at the annual meeting of the IUPAC Subcommittee on Solubility and Equilibrium Data in La Grande-Motte (France) in September 2011. The slide lists some of his main research interests.

Most of the papers cover solubility phenomena, ranging from gas solubilities in deep eutectic solvents (Marcus) and in liquid water near the temperature of the density maximum (Battino et al.), to liquid-liquid solubilities and salting-out effects (De Visscher), and to various solidliquid systems including $\mathrm{Np}(\mathrm{VI})$ solubility in alkaline $\mathrm{CaCl}_{2}$ solutions (Fellhauer et al.), the solubility of a difficult-to-synthesise calcium magnesium phosphate, whitlockite (Magalhães and Costa), the solubility of calcium molybdate and Mo(VI) speciation at $573 \mathrm{~K}$ (Dadze et al.) and the solubility isotherm in the lithium nitrate-potassium nitrate-water system at $373 \mathrm{~K}$ (Voigt and Voigt). Other studies deal with the spontaneous crystallisation of sodium sulfates and selenates (Balarew et al.) and of glycine-zinc halide compounds (Tepavitcharova et al.) from aqueous solution, as well as with applications of solubility to the precipitation of silica in industrial processes (Vielma et al.), the gravimetric analysis of perchlorate (Hefter) and the formation of stones in the urinary tract (Wang et al.; Grases et al.).
Thermodynamic consistency among solubility and calorimetric quantities was another focus of Professor Gamsjäger's work. In this vein, papers on the accurate measurement (Morishita et al.) and new correlation methods (E. Gamsjäger and Wiessner) for standard heat capacities and entropies, as well as a CALPHAD-type evaluation of the copper sulfate-water system (Höffler and Steiger) are presented in this memorial issue.

Several papers reflect Professor Gamsjäger's passion about the mathematical structure of thermodynamics ( $\mathrm{Pa}$ jarre et al.), the calculation of aqueous phase diagrams (Pelton et al.) and equilibrium calculations for metallurgical systems at high temperatures (Saxena et al.).

The accurate measurement of speciation equilibria, including surface complexation, was among Professor Gamsjäger's earlier research interests. A paper on speciation and equilibria in the acidic aluminium polyacrylic acid system (Lützenkirchen and Sjöberg) is in part based on his work. Other papers in the area of applied solution chemistry report transition metal complexes of Schiff bases and their biological activity (Knittl et al.), the measurement of physicochemical properties of ionic liquids (Andresová et al.) and aqueous carbonated trimethylamine solutions (Kolliopoulos et al.), new insights into the analysis of germanium in soils (Biver and Filella), an application of non-equilibrium thermodynamics to membrane separation processes (Toikka) and the effect of ion-exchange equilibria on the photocatalytic properties of layered oxides (Rodionov et al.).

The diversity and creativity of these contributions pay homage to Professor Gamsjäger's ability to inspire and interact with his colleagues. His advice, scientific integrity and friendliness will be missed deeply.

LanChi and Erich Königsberger, Guest Editors Murdoch, Western Australia Peter Gärtner, Editor-in-Chief Vienna, Austria 